\title{
I Found Myself at this Practicum: Student Reflections on Field Education
}

\author{
Sabrina Williamson \\ Carol Hostetter \\ Katherine Byers \\ Pamela Huggins
}

\begin{abstract}
The field experience is understood to be pivotal in social work education. In this qualitative study, BSW students reflected on their learning outcomes and processes in their field experiences. They highlighted how their work in agencies helped them to operationalize social work values and ethics, develop an awareness of themselves as social workers, and enhanced their confidence. Implications for strengthening the practicum experience though more reflective experiences and enhancing the preparation of field instructors is discussed.
\end{abstract}

Keywords: Field education, reflective practice

\section{INTRODUCTION}

For most BSW students, the field practicum is the first setting in which they are able to integrate and apply social work theory, values, skills, and knowledge under the supervision of a professional social worker (Barretti, 2004; Dalton, Stevens, \& MaasBrady, 2009; Vayda \& Bogo, 1991). The field placement is where students put into practice what they have learned in the classroom with respect to micro, mezzo and macro skills and also with respect to upholding professional values and following ethical codes of conduct.

Though field coordinators and other faculty serve as liaisons to the student and the field instructor throughout the course of the practicum, there are many experiences that students have with their field instructors apart from those listed in the learning plan and discussed in the field seminar. As students near graduation and prepare for either their first professional positions or further education, a more complete picture of their field experiences can be gained from gathering their reflections on their field experiences in a way that differs from the typical final input they may have in their evaluations with their field instructors or faculty liaisons.

One obvious benefit to this data gathering process is that the student reflections can be used to assess strengths and limitations in current field placement settings. More importantly, however, the authors posit that this time for self-reflection on practice (Furman, Coyne, \& Negi, 2008) is, of itself, an essential aspect of students' learning. As students recount meaningful experiences in their field placements, they have the opportunity to explore these experiences in a different way, critically reflect upon them,

Sabrina Williamson, Ph.D., and Carol Hostetter, Ph.D., are Associate Professors, and Katherine Byers, Ph.D., is Associate Professor and Director of the BSW Program, all at the Indiana University School of Social Work, Bloomington campus. Pamela Huggins, MSW, ACSW, LCSW, is an Associate Clinical Professor at the Saint Louis University School of Social Work. 
and perhaps develop a new perspective on the situation. While this process has the immediate effect of helping a student reflect on his or her current level of professional development, this process may also model for students the importance of continued reflection on their professional practice.

Obtaining student reflections on their field placements can also be of benefit to social work programs seeking accreditation or reaccreditation. In 2008, the Council on Social Work Education (CSWE) outlined revised educational policy and accreditation standards (EPAS). The EPAS clearly define that field education is the "signature pedagogy" for the social work profession (CSWE, 2008, p. 8). In other words, the field education component is the primary venue in which social work students are socialized to be professionals (CSWE, 2008). In accordance with the new EPAS, schools and departments of social work are called upon to demonstrate an "integrated curriculum" for classroom and field (CSWE, 2008, p. 9). Given the renewed importance of demonstrating student outcomes in the field, and the fact that educators will be dependent on student products to illustrate outcomes, it is critical to understand not only what students learn in the field, but also to understand how they reflect on their learning, and how they make connections between the classroom and the field setting.

This paper presents findings from a larger study in which faculty in a baccalaureate social work program in the Midwest engaged in a self-study of the field program. The focus of this paper is to share student reflections on their professional development and offer some implications for social work education that will enhance the ways in which social work faculty work with students to build a foundation for their professional development.

The following section of the paper includes a brief review of the relevant literature. Next is an explanation of the methodology employed in the larger study and a discussion of student reflections. The paper concludes with a discussion of limitations and an offering of the implications for social work education.

\section{REVIEW OF FIELD EDUCATION LITERATURE}

Social work educators expect the transfer of learning from classroom to practice to occur in the field practicum, with field instructors providing the primary, on-site supervision of that transfer (Cavazos, 1996; Knight, 2001). The practicum serves as the experience in which students are able to integrate and apply social work theory, values, skills, and knowledge (Bogo, 2005; Vayda \& Bogo, 1991). In the field, students develop practice skills; apply theory to actual practice situations, and otherwise "test their ability to be professional social workers" (Fortune, McCarthy, \& Abramson, 2001, p. 111). There is a substantial and growing literature on various aspects of field instruction. Researchers have studied the motivation to become field instructors (Bogo \& Power, 1992; Globerman \& Bogo, 2003), student satisfaction in the field (Fortune et al., 2001), learning opportunities valued by students (Fortune \& Kaye, 2002; Fortune et al., 2001), availability of field instructors to students (Barretti, 2009), student performance (Fortune et al., 2001; Zosky, Unger, White, \& Mills, 2003), and student motivation in the field practicum (Fortune, Lee, \& Cavazos, 2005). 
A link between reflection and learning has been discussed in the social work literature (Mishna \& Bogo, 2007). Mishna and Bogo define reflection on practice as “... reflection after the experience to derive learning and new understanding from a situation" (2007, p. 531). A compatible definition, although broader, is that reflection involves "those intellectual and affective activities in which individuals engage to explore their experiences in order to lead to new understandings and appreciations” (Boud, Keogh, \& Walker, 1985, p. 19). Ellis (2001) emphasizes the confidence that can result from reflective practice, enabling the student to better deal with future practice challenges. D'Cruz, Gillingham, and Melendez (2007) also propose that using reflections to acknowledge uncomfortable emotions such as anxiety can promote a stronger field instructor and student relationship. From this fertile soil, self awareness can occur and subsequently can enhance practice (D’Cruz et al., 2007). Lam, Wong, and Leung (2007) found that disturbing events and the self-discovery reflected in student reflection logs during practicum aided the learning process, particularly by focusing on “... individual values, beliefs, strengths and weaknesses” (2007, p. 96).

\section{METHODS}

\section{Research Design}

At the beginning of this study, the authors committed to using a collaborative, strengths-based (Saleebey, 2008) approach in their interviews with students. This primarily involved providing a space to hear the voices of students as they shared their experiences and reflections on their own learning. Specifically, the interviewers asked questions to draw out students' capacities and assets as they reflected on their field work in addition to asking about challenges that were faced.

\section{Description of Sample}

Data for this study were collected over the course of three academic years. All graduating seniors in three cohorts $(\mathrm{N}=74)$ were invited to participate in the study and 38 chose to participate. All participants were students on the same campus of a large, public, Midwestern university. The sample was $95 \%$ female, and $92 \%$ were of a traditional student age, between 21 and 23 at the time of the interview. All sample members except one were full-time students who completed each of their field placement experiences in either the home county of the university, or in one of the surrounding counties. The remaining member of the sample had been a part-time student for several years. This sample accurately mirrors the student body of the social work program on campus. Likewise, the participants' field placement sites were representative of all available practicum sites.

Of the field placement experiences, $31 \%$ were in a public school system; $31 \%$ were in non-profit agencies serving youth or families; $13 \%$ were in a non-profit agency providing services to people experiencing homelessness; $7 \%$ were in public or private agencies providing services to older adults; $7 \%$ were in a non-profit agency providing services to people experiencing domestic violence and the remaining field placements 
(11\%) were in various settings including those for addictions treatment, community development programs, and political or legal settings.

\section{Data Collection and Analysis}

At the time of data collection, the program under study utilized a model of field placements that had students completing one practicum placement in their second semester of the junior year (15 hours a week on average) and completing a second placement in the first semester of senior year (20 hours a week on average). This arrangement afforded students with learning opportunities in two different agencies which meant that they gained experience working with a broader array of client populations and challenges.

The sample was one of convenience, with the use of inclusionary criteria in order to create a purposive sample (Patton, 2002). Sample members $(n=38)$ all met the following criteria; seniors in an undergraduate social work program who had completed two semesters of field placement (the first in the spring of the junior year and the second in the fall of the senior year) and who were in their final semester of academic course work.

A structured interview protocol was developed to ensure the comparability of data obtained across sample members and researchers (Maxwell, 1996). The interview protocol is found in Table 1.

\section{Table 1. Interview Protocol}

1. Tell me about your first field placement.

a. Probes: Where was it? What were some significant learning experiences you had? To what extent was it a fit for you?

2. Tell me about your field supervisor at your first field placement.

a. Probes: Did he or she have an MSW or BSW? What did he or she do to facilitate your skill development?

3. Tell me about some of the ways you saw your skills develop at this practicum.

4. Tell me how you saw core values of social work embodied.

5. Tell me about your second field placement:

a. Probes: Where was it? What were some significant learning experiences you had? To what extent was it a fit for you?

6. Tell me about your senior year field supervisor.

a. Probes: Did he or she have an MSW or BSW? What did he or she do to facilitate your skill development?

7. Tell me about some of the ways you saw your skills develop at this practicum.

8. Tell me how you saw core values of social work embodied.

9. Anything else you want to say about your field placement experiences at IUB? 
Interviews were conducted for three cohorts of BSW seniors over the course of three academic years. All interviewers were faculty members in the School of Social Work at the same university but none had responsibility for field placement or field liaison duties. The use of the structured protocol, by which participants were asked a set of questions about their first field placement and then were immediately asked the same set of questions about their second field placement, addressed the challenge of obtaining comparable information from each student about each of their two placements.

Data collection and analysis occurred simultaneously. One interviewer/researcher had primary responsibility for analysis. The strategy of open coding (Strauss \& Corbin, 1990) was used to identify themes that emerged from the raw data. As similar themes emerged, the researcher grouped like codes together in order to form conceptual categories. The interview transcripts, codes, and conceptual categories were shared with the co-principal investigator for feedback and continued analysis. As additional interviews were completed, initial codes were referred to in a process of constant comparison (Strauss \& Corbin, 1990). As interviews were conducted just prior to the students' graduation ceremonies, member checks could not be employed.

\section{FINDINGS}

The findings presented here center on the reflections that students provided concerning their professional development. It is important to note that, no matter their overall perceptions about the agency or satisfaction with their field instructors, all participants reflected that learning and development had occurred in the field placement. One student summarized it well when she said, “...this is where the light popped on.”

The experience of having the light "pop on" was echoed, to some extent, by every participant. This self-awareness of knowledge and skill emerged because the students got to do "in real life" the things they had practiced in their classes. For example, students discussed recording and documentation responsibilities, assessments they had conducted, referrals they had made, and ways in which they had built rapport with clients. While this discussion of practicum learning is always reassuring for a faculty member/researcher to hear, there was little that was surprising in this recounting of tasks and meaningful experiences because of the general expectation that students will practice these types of skills in their practicum placements.

More provocative, however, in terms of thinking about social work pedagogy, were the students' reflections on what we categorized as becoming a social worker. This category captures the major themes that students discussed when they were reflecting on their field experiences. Within this category were three primary themes: values and ethics, awareness of self in practice, and confidence. Students reflected on each of these as being a part of their growth from social work student to professional social worker.

\section{Values and Ethics}

The way in which students articulated their perceptions of values and ethics in the field indicated that this was an area of importance for them. Students clearly saw that, the majority of the time, social workers operated with a set of ethical standards and values 
different from those held by other staff in the setting. Major themes that emerged included the importance of maintaining confidentiality, establishing professional boundaries, and operationalizing the social work value of dignity and worth of the person.

Some students spoke about confidentiality being broken in ways such as "having staffing in a room next to the lobby, when people can hear through the door" and having an unlocked records room, "where clients actually got in and read other clients' files." Other students gave examples of non-social work staff talking about clients in break rooms of agencies and of staff in general leaving "confidential paperwork out where the public could see it.”

Another theme that emerged related to values and ethics was that of boundaries between professionals and clients. One interviewee stated that while confidentiality at her agency was observed in a way that she expected, she was surprised by the lack of boundary setting by the staff (none of whom was a social worker), that they were "really close with the teens, and sharing personal things with them." Another student reflected that in her placement, there was another student intern from a different discipline, and that while the person's clinical skills were good, "she has no clue about setting boundaries with clients."

Though there were instances other than the ones above related to non-social workers and boundary issues, more often our interviewees discussed being relieved that a social worker in their setting had modeled for them the importance of establishing and maintaining boundaries. One student reflected that "boundary building was the biggest skill I accomplished" in the first placement, and another student shared,

The other thing I learned a lot about is dual relationships and boundary issues.

The men would ask you out, ask for your phone number and stuff like that. [My

field instructor] told me, taught me how to handle this. She also helped me to

learn to set boundaries with clients who only wanted to talk to me for hours on end.

In terms of operationalizing dignity and worth of the person, students were quick to point out ways in which they saw this value enacted and ways in which the agencies and staff members fell short of this goal. One student, a self-identified "investigator," said that she had grown the most at one of her placements in her ability to demonstrate dignity and worth. "Families are definitely treated with a lot of respect and dignity, even when they are extremely challenging. No matter how challenging a family presents, there is always someone who can look for the strengths and propose a way of how to use them." Another student, placed at a shelter for survivors of domestic violence, said,

We talk a lot about client self-determination in social work. In that practicum I was challenged by that, to really put that into practice. Facilitating a group where women had a desire to return to abusers was challenging. I really wanted to say 'don't go back there' - but I had to learn how to explore this with them.

In anything related to values and ethics, it was clear that the soon-to-be-graduates held social workers to a higher standard than they did other professionals because of the 
Code of Ethics (NASW, 1999). When social workers were observed to be in violation of the letter or spirit of the Code, the students were more distressed than when staff members from other disciplines took actions that were in conflict with social work values. One student said that while her supervisor was "compatible with social work values," another social worker, in charge of recruiting patients, had values that "were off the chart, in the wrong direction, in terms of trying to get people to come to [the agency] for services." Another student talked about some inappropriate signs and bumper stickers on the office wall that belonged to her (social work) supervisor and still another student talked about how one of the social workers had handled confidential information inappropriately.

Throughout the interviews, it was evident that students had learned a great deal about social work values and ethics in their coursework. As they were interviewed, most related situations that demonstrated that they not only understood the social work value and ethical framework but also embraced it as the desirable framework for effectively serving clients and developing an awareness of appropriate boundaries.

\section{Awareness of Self in Practice}

The majority of study participants shared how one or both of their practicum experiences helped them find their niche in social work. As one student said, "I found myself at this practicum.” Many interviewees, however, also realized that working with people who are vulnerable is not about "warm fuzzies" for the social worker. Similarly, one student shared, "Trying to find local low-income housing for people was a huge challenge. Sometimes it seemed hopeless but I still had to be hopeful. It was hard because some times there were not the best options available to a mother with three children and addiction problems.” Along these lines, another student stated,

My knowledge base grew about what it was really like to deal with clients. We

have these theories at school, and a homework assignment, and it seems like there

is a right answer. But in real life with real clients, it takes awhile to come up with answers.

Students also realized that they needed to be aware of their own strengths and weaknesses in terms of coping with stress and interacting with others. Talking about her increased confidence, one student said, "I became more comfortable in communication, and was seeing how what I said affected clients. I learned how to not overpower them..." Also in this regard, a student shared, "We had to do drug screens and house searches. Those are pretty personal. It forced me to be professional and not take things personally. I became more aware of my own limitations.... I learned to be open with my supervisor so she could help me with situations." Another interviewee remembered a time when "there was a client that I had talked to a lot...she blew up at me when she was having conflict with another person. She threatened me, but I knew how to make contact with her because of [my relationship with her]. After it happened I broke down and was shaking."

The impact of challenging practicum experiences clearly prompted awareness of self in a way that classroom discussions and activities may not. As a group, students reporting challenging and uncomfortable experiences in the practicum were also able to follow up 
with a self appraisal of how their actions, communications, and/or skill development changed as a result. This self awareness seemed vital as well as they worked on becoming social workers.

\section{Confidence}

Not surprisingly, almost every study participant reflected on his or her confidence and how it had grown during field placements. Most of the respondents talked about feeling an increase in confidence in interacting with clients and colleagues, feeling as though they had a professional voice in addition to feeling more confident about their skill set. One student faced many challenges at one of her placements, including being one of the few social workers in a legal setting. Despite her frustrations, she shared,

I am still processing that placement. I am angry at school for putting me in a place where I wasn't supported. That's been difficult for me, and for the other person who was placed there, but I also have these moments where I think 'wow I haven't been so challenged in a long time'....I ended up figuring out how to have a strong voice.

Another student articulated, "I think practicum really makes you understand whether you are cut out for social work or not.” Clearly, students found the practicum experience to be the primary venue for developing confidence in their abilities to be good social workers.

\section{Summary of Findings}

In asking students to reflect on their learning in the BSW field placements, three important themes were identified. First, their knowledge and skills went beyond identifying values and ethical issues in practice. The students demonstrated a strong ability to analyze practicum situations and how unethical approaches might adversely affect the client or themselves. This finding was especially supported by their reported discomfort in observing non-social workers' approaches with clients and by their experiences in setting professional boundaries.

Second, students recognized that self awareness was a part of becoming a professional social worker. Self-awareness was seemingly promoted at times when the students felt uncomfortable or were confronted with the realities of some social problems. Finally, as students reflected on their practicum experiences, the increase in their level of confidence from the beginning to the end was an important product of the overall learning in the practicum. The findings underscore the importance of Barretti's statement that “... a socialized identity is not a continuous process of reacting passively to curricular knowledge and professional experiences but may depend more on students' negotiations of their dilemmas and interactions with significant others” (2004, p. 277).

\section{LIMITATIONS TO THE STUDY}

As with any qualitative study, a primary limitation for this research lies in the inability to generalize findings to the larger population. Another limitation to the study 
involves the use of interviews as a primary source of data collection and analysis (Padgett, 1998). One element of this limitation lies in the chance that the respondent in an interview may give answers that he or she feels are socially desirable. To counteract this possibility, all respondents were reminded prior to the interview that their names would remain confidential, and that the purpose of the study was to learn about the strengths and challenges of their field placements, not to "name names" for purposes of reward or criticism. Additionally, the interviews were conducted in the spring semester of the participants' senior year and interviewers did not have the participants in class at the time. Consequently, students did not have to be concerned that their interview responses would affect their grades.

Another aspect of the limitation to conducting interviews lies in the chance that the researcher/interviewer may be the source of bias or error (Patton, 2002). It is possible that the researcher's verbal and nonverbal cues prompted the respondent's discussion and reflection in some cases, and inhibited it in others. To minimize the impact of researcher bias, semi-structured protocols were used. The use of the protocols increased the likelihood that questions and probes were used uniformly.

\section{IMPLICATIONS FOR SOCIAL WORK EDUCATION}

The results of this study have implications for teaching, research, and the overall approach to field education. The study validates that the practicum, the signature pedagogy (CSWE, 2008; Shulman, 2005) of social work, is critical in helping students find themselves and enhance their development as social workers. As a result, social work education should continue to focus on the overall quality of field education through a number of current and specific ways.

The current EPAS for social work education include ten core competencies with articulated practice behaviors for each. The field placement is a logical, even necessary, venue in which to demonstrate student achievement of these competencies and behaviors. As social work educators and administrators begin to prepare for accreditation and reaccreditation processes, it is important to continue obtaining students' perspective on their practicum work. The process of determining whether or not, and to what extent, a program's graduates demonstrate mastery of a particular competency cannot be done without student input. While many programs likely have an understanding the nature of experiences that students routinely have in the field, it is also important to understand how the students are processing their own learning.

One possibility would be to engage in this type of reflective process with students as we are reviewing "products" from their practicum work (i.e. assessments, genograms, process recordings, etc.). By doing this, we can ascertain not only how students performed that task at a particular point in time, but we will also be able to understand how they took that initial feedback (whether a grade or field instructor evaluation) and used it to further their own knowledge in this area.

The findings from this study also provide guidance to social work educators regarding the "implicit curriculum" identified in the new EPAS (CSWE, 2008, p.10). The implicit curriculum is defined as the environment in which the explicit curriculum is 
delivered. The training and support of field instructors can certainly be considered an aspect of the implicit curriculum. Social work education must move beyond a brief field instructor orientation to an advanced educational or training module which assists field instructors to develop and use strategies that systematically explore values and ethics, develop self awareness, and build confidence.

While many field education programs focus on aspects of strong supervision, this study underscores the need to help field instructors develop as teachers and develop daily or weekly strategies to promote student reflection as a key part of their learning. Some of the current tools, such as process recording, journaling, values conflict discussions, and case analysis, continue to be useful in the ongoing development of the thinking of a social worker. Each of these assignments is included in courses leading up to the field placement, as well as in the field seminar, in the program where the study was conducted. In the interviews, students identified these assignments as being helpful transitions from the classroom to the field. To the extent that field instructors can be more aware of classroom tools and assignments, they will be even better prepared to reinforce learning.

The skills needed for ongoing reflection could also aid the field instructors in their own professional practice. Then, in turn, they would become stronger role models and mentors for future students. In addition to the focus on the school's responsibility to train field instructors, schools of social work should also evaluate potential placements for an environment where the student would have the time and interest from a field instructor who would go beyond the minimal teaching tasks. As Kanno and Koeske assert, the quality of field instruction is highly important for student satisfaction and sense of efficacy (2010, p. 34).

The value of integrative seminars is underscored as another important part of the socialization process as a student becomes a professional social worker (Barretti, 2009). The seminars provide many assignments requiring students to reflect in a focused way on practicum experiences and their reactions. While seminars are primarily viewed as providing support to students in the field, the opportunities apart from the rest of the curriculum for verbal and written reflection promoting self-awareness tend to be greater in these settings. As students discuss client situations, values and ethical challenges, or broader social issues, they are able to add to their practice skills and knowledge. Additionally, they are able to build on their self-awareness and confidence. The key factor for successful integrative seminars would be to ensure that they are studentcentered, with students teaching other students through case presentation and analysis, peer feedback, and consultation models. In addition to integrative seminars, social work programs could design an overall program assessment or plan that engages students in reflection at several points in their journey toward the degree. These assessments could range from a series of questions where students respond in a reflective journal or paper to an added dimension to existing assignments. This engagement would foster development and confidence through on-going self awareness and appraisal. Faculty would need to commit to completing the loop through providing feedback and assistance in response to reflections. Professional socialization of social work students is complex and challenging, and the literature at this point raises more questions than it answers (Barretti, 2004). 
Many "Introduction to Social Work" courses have reflection assignments based on volunteer work or reactions to various target populations or social challenges. These opportunities can continue as we engage students to think critically and reflect on new information that is provided in policy or human behavior courses as well. As we teach in relation to social work practice, students also see the holistic attention as they move from student role in class to practicum student, prepared for the field.

Lastly, the study has implications for social work research. Though important, research on field education continues to be lacking. Select reflection papers, journals, or assignments could be analyzed using qualitative analysis. Pre- or post-testing could be designed around the themes identified in this study: infusion of values and ethics, the value of self awareness, and the importance of building confidence. Further study could focus on a comprehensive exploration of the student's experience by comparing the field instructor's and student's perceptions in these areas. Additionally, research on students' view of the discrepancies between their ideal of social work practice and their lived experience of it would be beneficial (Barretti, 2009).

\section{CONCLUSION}

Through asking students to reflect on learning experiences in the practicum, social work educators are able to know more about preparing the next generation of social workers. This study has reinforcing implications for many current methods employed in social work education such as integrative seminars, orientation and selection of field instructors, and use of various assignments. Assignments such as journals, process recordings, supervision meetings and other activities that promote self-awareness and reflection appear to be especially important in the development of social work practice skills (Lam et al., 2007). Additionally, the study sheds light on the importance of additional factors not always addressed in a practicum evaluation, such as the growth and development of confidence and awareness of self. It also focuses attention on the need to provide advanced education for field instructors to help them develop as stronger "teachers" in the field. In addition to the many wonderful learning moments that can and do happen in social work classrooms, there is no substitute for guided learning in the field. As one student reflected,

Watching my supervisor was the most beneficial learning experience that I've had in any environment. She's a very centered, balanced person who knows what she's doing. She was able to convey that, to teach by example and not by being directive, with staff, parents, kids, me.... When I was dealing with certain circumstances, I would think about her and draw on her.

This student echoes the findings about the power of positive modeling by field instructors on professional socialization (Barretti, 2009).

Clearly, the practicum remains integral to social work education and all efforts to further understand how students learn in this pedagogy will serve to continue to enhance the quality and outcomes of the experience. 


\section{References}

Barretti, M. (2004). What do we know about the professional socialization of our students? Journal of Social Work Education, 40(2), 255-283.

Barretti, M. (2009). Ranking desirable field instructor characteristics: viewing student references in context with field and class experience. The Clinical Supervisor, 28(1), 47-71.

Bogo, M. (2005). Field instruction in social work: A review of the research literature. The Clinical Supervisor, 24(1/2), 163-193.

Bogo, M., \& Power, R. (1992). New field instructors’ perceptions of institutional supports for their roles. Journal of Social Work Education, 28(2), 178-189.

Boud, D, Keogh, R., \& Walker, D. (Eds.). (1985) Reflection: Turning experience into learning. New York: Kogan Page.

Cavazos, A. (1996). Measuring BSW student learning in field instruction. Journal of Social Work Education, 32(3), 329-398.

Council on Social Work Education. (2008). Educational policy and accreditation standards. Alexandria, VA: Author.

Dalton B., Stevens, L., \& Maas-Brady, J. (2009). Surveying the BSW field director. The Journal of Baccalaureate Social Work, 14(2), 17-29.

D’Cruz, H., Gillingham, P., \& Melendez, S. (2007). Reflexivity, its meanings and relevance for social work: A critical review of the literature. British Journal of Social Work, 37, 73 -90.

Ellis, G. (2001). Looking at ourselves-Self-assessment and peer assessment: Practice examples from New Zealand. Reflective Practice, 2(3), 289-302.

Fortune, A. E., \& Kaye, L. (2002). Learning opportunities in field practica: Identifying skills and activities associated with MSW students' self-evaluation of performance and satisfaction. Clinical Supervisor, 21(1), 5-28.

Fortune, A. E., Lee, M., \& Cavazos, A. (2005). Special section: Field education in social work achievement: Motivation and outcome in social work field education. Journal of Social Work Education, 41(1), 115-129.

Fortune, A. E., McCarthy, M., \& Abramson, J. S. (2001). Student learning processes in field education: Relationship of learning activities to quality of field instruction, satisfaction, and performance among MSW students. Journal of Social Work Education, 37(1), 111-124.

Furman, R., Coyne, A., \& Negi, N. J. (2008). An international experience for social work students: Self-reflection through poetry and journal writing exercises. Journal of Teaching in Social Work, 28(1/2), 71-85. 
Globerman, J., \& Bogo, M. (2003). Changing times: Understanding social workers' motivation to be field instructors. Social Work, 48(1), 65-76.

Kanno, H., \& Koeske, G. F. (2010). MSW students’ satisfaction with their field placements: The role of preparedness and supervision quality. Journal of Social Work Education, 46(1), 23-38.

Knight, C. (2001). The process of field instruction: BSW and MSW students' views of effective field supervision. Journal of Social Work Education, 37(2), 357-380.

Lam, C., Wong, H., \& Leung, T. (2007). An unfinished reflexive journey: Social work students' reflection on their placement experiences. British Journal of Social Work, 37, 91 -105.

Maxwell, J. A. (1996). Qualitative research design: An interactive approach. Thousand Oaks, CA: Sage Publications.

Mishna, F., \& Bogo, M. (2007). Reflective practice in contemporary social work classrooms. Journal of Social Work Education, 43(3), 529- 547.

National Association of Social Workers. (1999). Code of Ethics. Washington DC: NASW.

Padgett, D. K. (1998). Qualitative methods in social work research: Challenges and rewards. Thousand Oaks, CA: Sage Publications.

Patton, M. Q. (2002). Qualitative research and evaluation methods ( $3^{\text {rd }}$ ed.). Thousand Oaks, CA: Sage Publications.

Saleebey, D. (2008). Commentary on the strengths perspective and potential applications in school counseling. Professional School Counseling, 12(2), 68-75.

Shulman, L.S. (2005, Summer). Signature pedagogies in the professions. Dæedalus, 134, 52-59.

Strauss, A., \& Corbin, J. (1990). Basics of qualitative research: Grounded theory procedures and techniques. Newbury Park, CA: Sage Publications.

Vayda, E., \& Bogo, M. (1991) A teaching model to unite classroom and field. Journal of Social Work Education, 27(3), 271-278.

Zosky, D. L., Unger, J. M., White, K., \& Mills, S. J. (2003). Non-traditional and traditional social work students: Perceptions of field instructors. Journal of Teaching in Social Work, 23(3/4), 185-201.

\section{Author's note:}

Address correspondence to: Sabrina Williamson, Indiana University Bloomington, 1127

E. Atwater, Bloomington, IN 47401. Email: sabawill@iupui.edu 